\title{
New enzyme-targeting radiosensitizer (KORTUC II) treatment for locally advanced or recurrent breast cancer
}

\author{
TAIJU SHIMBO $^{1}$, MIO NAKATA ${ }^{1}$, HIROTO YOSHIOKA ${ }^{1}$, CHIKARA SATO $^{1}$, AKIHIRO HORI ${ }^{1}$, KOSEI KIMURA ${ }^{2}$, \\ MITSUHIKO IWAMOTO ${ }^{2}$, KEN YOSHIDA $^{3}$, YASUO UESUGI ${ }^{4}$, HIRONORI AKIYAMA $^{5}$ and KEIJI NIHEI ${ }^{1}$ \\ Departments of ${ }^{1}$ Radiation Oncology, and ${ }^{2}$ Breast and Endocrine Surgery, Osaka Medical College, Takatuki, Osaka 569-8686; \\ ${ }^{3}$ Department of Radiology, Kansai Medical University Medical Center, Moriguti, Osaka 573-1191; \\ ${ }^{4}$ Department of Rehabilitation, Kansai University of Welfare Sciences, Kashiwara, Osaka 583-0026; \\ ${ }^{5}$ Department of Dental Radiology, Osaka Dental University, Hirakata, Osaka 573-1121, Japan
}

Received June 7, 2021; Accepted August 16, 2021

DOI: $10.3892 / \operatorname{mco} .2021 .2388$

\begin{abstract}
Kochi oxydol radiation therapy for unresectable carcinomas II (KORTUC II) is currently the most widely used radiosensitizer in Japan. This sensitizer is a solution consisting of $0.83 \%$ sodium hyaluronate and $0.5 \%$ hydrogen peroxide. The mixture is injected intratumorally just before radiation therapy (RT) several times. KORTUC II has the effect of neutralizing antioxidant enzymes, while increasing the oxygen tension into the tumor tissue, and achieves marked local effects without notable adverse events. The present report describes cases in which KORTUC II was used to treat patients with locally advanced breast cancer (LABC) or recurrent breast cancer (LRBC). The present study included 30 patients with LABC $(n=9)$ or LRBC $(n=21)$ aimed at local control of tumors, who were followed up for $\geq 3$ months after treatment. The irradiation dose and extent fields were determined by the attending physicians considering various patient factors, such as a performance status, prognosis and presence or absence of adjuvant therapy. The median irradiation dose was 60.4 Gy3.5 (43.6-76.1 Gy3.5) based on the calculation of equivalents of 2 Gy fractions, and the median total number of sensitizer injections was 5 (2-7) times. The median maximum tumor shrinkage was $97.0 \%$ and 15 patients $(50 \%)$ were assessed to have achieved a clinical complete response. The proportion with loco-regional control at 1,2 and 3 years was $100,94.7$ and $75.4 \%$, respectively, and progression free survival after RT at 1 and 2 years was 59.0 and $24.1 \%$, respectively. KORTUC II exhibited high rates of local tumor control for LABC and LRBC. KORTUC II is expected to be
\end{abstract}

Correspondence to: Dr Hiroto Yoshioka, Department of Radiation Oncology, Osaka Medical College, 2-7 Daigaku-cho, Takatuki, Osaka 569-8686, Japan

E-mail: rad111@osaka-med.ac.jp

Key words: Kochi oxydol radiation therapy for unresectable carcinomas, radiosensitizer, locally advanced breast cancer, locally recurrent breast cancer, sodium hyaluronate, hydrogen peroxide an inexpensive and promising RT method because it is safe and has an excellent radio-sensitizing effect.

\section{Introduction}

Symptoms such as bleeding and tissue breakdown due to progression of locally advanced breast cancer (LABC) and locally recurrent breast cancer (LRBC) are events that lead to a reduction in quality of life (QOL), and it is often difficult to deal with them because the symptoms cannot be alleviated at the terminal stage. Surgical treatment is difficult for advanced lesions that cannot be controlled by radiation therapy (RT). If RT enables local control, the patient's QOL will improve. However, LABC and LRBC are often situations in which drug therapy is ineffective, and it is difficult to obtain local control with RT alone, because such lesions contain numerous hypoxic cancer cells and antioxidant enzymes that may confer resistance to RT (1-3).

\section{Subjects and methods}

Patient selection. At our institution, KORTUC II treatment was performed after detailed informed consent given in written form was obtained from patients who were expected to survive at least a year and met the following additional criteria: i) Local control by conventional radiotherapy alone was presumed to be difficult; ii) the dosage of additional irradiation they could receive was limited; and iii) they refused surgery as a treatment option. Hormone therapy or systemic chemotherapy was used concomitantly in some patients according to the judgment of the attending breast surgeon and the patient's wishes. KORTUC II treatment was approved by Osaka Medical College Clinical Trials Registry, trial no. 1973, (May 10, 2010) and UMIN Clinical Trials Registry, trial no. UMIN000003734, (June 10, 2010).

Of the 37 patients treated with KORTUC II for LABC or LRBC between February 2011 and January 2020, the 30 patients who were followed up for at least 3 months after treatment were included in the study. These subjects consisted of 9 patients with LABC ( 1 in stage IIIA, 5 in stage IIIB, and 3 in stage IV) and 21 patients with LRBC. 
Radiotherapy. RT was performed for the purpose of local control with external beam irradiation (X-ray or electron beam) to locally advanced lesions, recurrent lesions or metastatic lesions of the breast, chest wall, axillary lymph nodes, and supraclavicular fossa lymph nodes. The dose and extent, as well as particular tumor sites to be irradiated, were determined by the attending physicians considering factors including tumor size and location, concomitant therapies, presence/absence of metastases outside the irradiation fields, and general condition of the patient.

In principle, the irradiation fields were to include all lesions for stage III LABC, and local areas that required local control for stage IV LABC and LRBC patients.

Dosing method of the sensitizer. This sensitizer is a solution consisting of $0.83 \%$ sodium hyaluronate and $0.5 \%$ hydrogen peroxide $\left(\mathrm{H}_{2} \mathrm{O}_{2}\right.$, also known as 'oxydol' in Japan) by volume. It is prepared aseptically before each use by adding $2.5 \mathrm{ml}$ of sodium hyaluronate (Adant ${ }^{\circledR}$ Dispo) and $1 \mathrm{ml}$ of $1 \%$ xylocaine to $0.5 \mathrm{ml}$ of oxydol and mixing them to be dispensed as a total volume of $4 \mathrm{ml}$ from a single vial. Our standard dosing protocol called for 1 vial for tumors $<3 \mathrm{~cm}$ in diameter, 2 vials for tumors $3-<5 \mathrm{~cm}$ in diameter, $\geq 3$ vials for tumors $\geq 5 \mathrm{~cm}$ in diameter, with a maximum dose of 5 vials for giant tumors. However, the optimal dose is still uncertain.

The sensitizer was injected into the tumor twice weekly immediately before RT either under direct vision in the case of tumors close to the skin, or under ultrasound or CT guidance. Under ultrasound guidance, when the sensitizer is injected into a tumor, oxygen is generated in the form of micro-bubbles and the tumor can immediately be recognized as a high echo area. The sensitizer was injected so that oxygen was distributed in the entire tumor. Usually, injections of the sensitizer occurred after the patient had already received approximately $20 \mathrm{~Gy}$ at the beginning of a course of RT. This was to prevent the increased intra-tumor pressure from the injections causing viable tumor cells to infiltrate into nearby lymphatic and blood vessels (5). To prevent dissemination along the injection route, punctures were made on the skin surface in the irradiation field, whenever possible.

Items examined. To examine the local effects, the tumor size was measured before treatment and at the estimated time of greatest regression (smallest volume) within 2 years after treatment. From this, the maximum tumor shrinkage (MTS) was calculated according to the percent decrease in tumor volume revealed by $\mathrm{CT}$ imaging at the estimated time of greatest regression. The tumor volume was measured based on CT images using the Eclipse radiation treatment planning system (Varian Medical Systems, Inc.). This interval to greatest regression was determined based upon prior studies using contrast-enhanced MRI that show, on average, 14 months are required between KORTUC II therapy and tumor disappearance according to RESIST criteria. However, there is no pre-determined protocol for scheduling follow-up imaging tests. In particular, CT scans to evaluate treatment effects were performed in a timely manner depending on the situations of individual cases. In addition to the CT-determined volume measurements, MRI, and PET-CT imaging were conducted when deemed appropriate to assess the presence and extent of any residual tumor in the treated area. The duration of loco-regional control (LC) was determined by the time in months at which tumor regrowth in the irradiated target lesion was noted by one of these imaging techniques, and this event indicated local recurrence. LC and duration of progression free survival (PFS) after the completion of RT were determined using the Kaplan-Meier method. In the case of LC and PFS, death of the subject was regarded a censoring event.

The irradiation dose was calculated as equivalents of 2 Gy fractions (EQD2) with the $\alpha / \beta$ ratio of 3.5 (breast cancer has a low ratio of $\alpha / \beta)$, and described as Gy3.5 $(7,8)$. Additionally, the subjects were divided into two groups, less than $60 \mathrm{Gy3} .5(60 \mathrm{~Gy}<)$ and $60 \mathrm{~Gy} 3.5$ or more ( $\geq 60 \mathrm{~Gy})$, and evaluated according to whether there was a statistically significant difference in number of sensitizer injections, MTS, duration of LC, and time to progression (TTP) using Student's t-test. Comparison of duration of LC and PFS between the two groups ( $60 \mathrm{~Gy}<, \geq 60 \mathrm{~Gy}$ ) was evaluated using the Kaplan-Meier method.

Statistical analysis. Survival periods were measured starting from the day after end of treatment. The tumor volume was measured by the radiotherapy planning device Varian (Varian Medical 85 Systems) Eclipse ver.11.0. Continuous variables are presented as mean \pm standard deviation. Categorical variables are presented as numbers (percentage). The Kaplan-Meier method was used to calculate survival analysis and the differences were compared using Wilcoxon rank sum test. Comparison between the 2 groups, differences in parameters depending on the irradiation dose filled was performed using the Wilcoxon rank sum test. All experiments were performed in duplicate. For analyses, EZR software, version 1.54 and statistical data analysis in Excel 2016 was used. $\mathrm{P}<0.05$ was considered to indicate statistically significant differences.

\section{Results}

Patients treated with KORTUC II. Table I shows the baseline patient characteristics. All of the 30 patients were women, and the mean age was 61 years (43-75 years). RT was performed at the median dose of $53 \mathrm{~Gy} / 19$ Fr (40 Gy/16 Fr-67.5 Gy/25 F). The median irradiation dose was $60.4 \mathrm{~Gy}_{3.5}\left(43.6-76.1 \mathrm{~Gy}_{3.5}\right.$ ). The median total number of sensitizer injections was 5 (2-7). Of the 30 patients, 22 patients were treated concomitantly with hormone therapy and 18 patients with chemotherapy. Concomitant treatment status for one patient was unknown. The median follow-up period was 19 months (3-106 months).

Tumor shrinkage rate by KORTUC II. Table II shows the therapeutic effects. The median baseline breast cancer tumor volume measured using CT, was $53.2 \mathrm{~cm}^{3}$ and the mean volume was $116.5 \mathrm{~cm}^{3}\left(4.2-642.5 \mathrm{~cm}^{3}\right)$. Following KORTUC II therapy, the median MTS was $97.0 \%$ (standard deviation=9.8\%) and the mean was $91.7 \%$ (range $77.2-100 \%$ ). Fifteen patients $(50 \%)$ were assessed to have achieved a clinical complete response (cCR) as a temporary effect. The median evaluation period until MTS was 8 months (2-17 months).

Loco-regional control and progression free survival. Tumor regrowth in treated lesions occurred in 4 patients (13.3\%) at 30, 
Table I. Patient characteristics.

\begin{tabular}{|c|c|c|c|c|c|c|c|c|c|c|}
\hline $\begin{array}{l}\text { Patient } \\
\text { no. }\end{array}$ & $\begin{array}{l}\text { Age, } \\
\text { years }\end{array}$ & Disease & Stage & $\begin{array}{l}\text { Irradiation } \\
\text { site }\end{array}$ & $\begin{array}{l}\text { Radiation } \\
\text { dose, Gy }\end{array}$ & $\begin{array}{c}\text { Number of } \\
\text { fraction }\end{array}$ & $\begin{array}{l}\text { EQD2 } \\
\text { Gy3.5 }\end{array}$ & $\begin{array}{l}\text { Number of } \\
\text { sensitizer } \\
\text { injections }\end{array}$ & $\begin{array}{l}\text { Hormonal } \\
\text { therapy }\end{array}$ & Chemotherapy \\
\hline 1 & 45 & LRBC & & $\mathrm{CW}$ & 44 & 18 & 48 & 4 & - & - \\
\hline 2 & 75 & LRBC & & $\mathrm{CW}$ & 40 & 16 & 44 & 7 & - & + \\
\hline 3 & 70 & LABC & IIIB & $\mathrm{CW}, \mathrm{Ax}$ & 67 & 25 & 77 & 6 & + & + \\
\hline 4 & 57 & LABC & IV & $\mathrm{CW}, \mathrm{Ax}$ & 59 & 21 & 69 & 7 & + & + \\
\hline 5 & 67 & LRBC & & $\mathrm{CW}$ & 53 & 19 & 61 & 5 & + & + \\
\hline 6 & 54 & LRBC & & $\mathrm{Br}, \mathrm{Ax}$ & 59 & 21 & 69 & 3 & + & + \\
\hline 7 & 56 & LRBC & & $\mathrm{CW}$ & 53 & 21 & 59 & 6 & UK & UK \\
\hline 8 & 60 & LRBC & & $\mathrm{Br}$ & 59 & 22 & 68 & 6 & - & - \\
\hline 9 & 67 & LRBC & & $\mathrm{CW}, \mathrm{Ax}$ & 58 & 25 & 62 & 6 & + & + \\
\hline 10 & 49 & LRBC & & $\mathrm{Br}$ & 58 & 29 & 59 & 5 & + & + \\
\hline 11 & 68 & LRBC & & $\mathrm{Br}, \mathrm{Ax}$ & 54 & 18 & 65 & 5 & + & - \\
\hline 12 & 75 & LRBC & & $\mathrm{Br}$ & 59 & 21 & 69 & 5 & + & - \\
\hline 13 & 58 & LRBC & & $\mathrm{CW}$ & 59 & 21 & 69 & 5 & + & + \\
\hline 14 & 73 & LRBC & & CW & 59 & 21 & 69 & 5 & + & - \\
\hline 15 & 75 & LRBC & & $\mathrm{Br}$ & 59 & 21 & 69 & 4 & + & + \\
\hline 16 & 67 & LRBC & & $\mathrm{CW}, \mathrm{Ax}, \mathrm{SC}$ & 60 & 30 & 60 & 3 & + & - \\
\hline 17 & 59 & LRBC & & $\mathrm{Ax}, \mathrm{SC}$ & 60 & 30 & 60 & 5 & + & + \\
\hline 18 & 72 & LABC & IV & $\mathrm{CW}$ & 44 & 16 & 51 & 3 & + & + \\
\hline 19 & 51 & LRBC & & SC, Neck & 60 & 30 & 60 & 2 & - & + \\
\hline 20 & 74 & LRBC & & $\mathrm{Br}, \mathrm{Ax}$ & 53 & 19 & 61 & 5 & + & + \\
\hline 21 & 74 & LABC & IIIB & $\mathrm{Br}, \mathrm{Ax}, \mathrm{SC}$ & 53 & 19 & 61 & 5 & + & - \\
\hline 22 & 52 & LRBC & & $\mathrm{CW}$ & 40 & 16 & 44 & 3 & + & + \\
\hline 23 & 43 & LRBC & & $\mathrm{CW}$ & 53 & 19 & 61 & 5 & - & + \\
\hline 24 & 58 & LRBC & & $\mathrm{Br}$ & 53 & 19 & 61 & 5 & + & + \\
\hline 25 & 61 & LRBC & & CW & 44 & 16 & 51 & 3 & + & + \\
\hline 26 & 43 & LABC & IIIA & $\mathrm{Br}, \mathrm{Ax}, \mathrm{SC}$ & 53 & 19 & 61 & 5 & - & + \\
\hline 27 & 48 & LABC & IV & $\mathrm{Br}, \mathrm{Ax}, \mathrm{SC}$ & 53 & 19 & 61 & 5 & + & - \\
\hline 28 & 59 & LABC & IIIB & $\mathrm{Br}, \mathrm{Ax}$ & 53 & 19 & 61 & 5 & + & - \\
\hline 29 & 52 & LABC & IIIB & $\mathrm{Br}, \mathrm{Ax}, \mathrm{SC}$ & 53 & 19 & 61 & 5 & - & - \\
\hline 30 & 70 & LABC & IIIB & $\mathrm{Br}, \mathrm{Ax}, \mathrm{SC}$ & 53 & 19 & 61 & 5 & + & - \\
\hline
\end{tabular}

LRBC has no description of staging due to recurrence status. LABC, local advanced breast cancer; LRBC, local recurrence breast cancer; Br, breast; $\mathrm{CW}$, chest wall; Ax, axilla; SC, supraclavicular fossa; UK, unknown; EQD2 Gy3.5, equivalent dose in 2 Gy fractions with the $\alpha / \beta$ ratio of 3.5 .

37,36 , and 12 months after treatment. The proportion of patients with enduring LC at 1,2, and 3 years was 100,94.7, and 75.4\%, respectively, as shown in the Kaplan-Meier curve (Fig. 1). Seventeen patients $(56.7 \%)$ presented with tumor exacerbation outside the irradiation field. The median duration of PFS was 9 months (2-62 months). Nine patients (30\%) died-eight of the primary disease, and one of other disease (pancreatic cancer). The proportion of patients with PFS after RT at 1 and 2 years was 59.0, and $24.1 \%$, respectively, as shown in Fig. 2. Two patients (nos. 6 and 23) developed chest wall necrosis in the irradiated area 2 and 3 months after RT, respectively.

Subgroup analysis between $60 \mathrm{~Gy}<$ and $\geq 60 \mathrm{~Gy}$. Table III shows that the difference in the calculated EQD2 between the two groups, $60 \mathrm{~Gy}<$ and $\geq 60 \mathrm{~Gy}$, was statistically significant $(\mathrm{P}<0.01)$. On the other hand, there was no significant difference in number of sensitizer injections $(\mathrm{P}=0.40)$, MTS $(\mathrm{P}=0.09)$, duration of LC $(\mathrm{P}=0.49)$, and TTP $(\mathrm{P}=0.30)$. There was no difference in duration of $\mathrm{LC}(\mathrm{P}=0.19)$ and $\mathrm{PFS}(\mathrm{P}=0.21)$ between the two groups, as shown in Figs. 3 and 4.

\section{Discussion}

Radiosensitizers have been widely studied as a method to enhance the effects of RT. Although a number of radiosensitizers, including misonidazole, were developed in the past (9-12), many of them have not been used in clinical settings due to adverse reactions such as peripheral neuropathy. In this context, KORTUC II, a new enzyme-targeting and radiation sensitizer developed at Kochi University, has gathered attention (1-6). The sensitizer contains $\mathrm{H}_{2} \mathrm{O}_{2}$ and hyaluronic acid as its main components, which, along with their decomposition 
Table II. Treatment effects.

\begin{tabular}{|c|c|c|c|c|c|c|c|c|c|c|}
\hline $\begin{array}{l}\text { Patient } \\
\text { No. }\end{array}$ & $\begin{array}{c}\text { Pre-TTV, } \\
\mathrm{cm}^{3}\end{array}$ & MTS, \% & $\begin{array}{c}\text { Temporary } \\
\text { effect }\end{array}$ & $\begin{array}{l}\text { Time } \\
\text { to MTS, } \\
\text { months }\end{array}$ & $\begin{array}{l}\text { Regrowth } \\
\text { in field }\end{array}$ & $\begin{array}{c}\text { LC, } \\
\text { months }\end{array}$ & $\begin{array}{l}\text { Regrowth } \\
\text { out of } \\
\text { field }\end{array}$ & $\begin{array}{l}\text { TTP, } \\
\text { months }\end{array}$ & $\begin{array}{l}\text { Follow up, } \\
\text { months }\end{array}$ & Prognosis \\
\hline 1 & 27.3 & 82.1 & cPR & 15 & - & 36 & + & 15 & 36 & AWD \\
\hline 2 & 32.4 & 100.0 & $\mathrm{cCR}$ & 6 & - & 88 & + & 21 & 88 & AWD \\
\hline 3 & 220.3 & 100.0 & $\mathrm{cCR}$ & 8 & + & 30 & + & 20 & 35 & DOD \\
\hline 4 & 397.8 & 94.1 & $\mathrm{cPR}$ & 12 & - & 35 & + & 21 & 45 & AWD \\
\hline 5 & 4.2 & 100.0 & $\mathrm{cCR}$ & 3 & + & 36 & + & 20 & 106 & AWD \\
\hline 6 & 240.5 & 100.0 & $\mathrm{cCR}$ & 3 & - & 6 & + & 3 & 6 & DOD \\
\hline 7 & 25.9 & 100.0 & $\mathrm{cCR}$ & 3 & - & 3 & - & 3 & 3 & NED \\
\hline 8 & 446.0 & 77.0 & cPR & 2 & - & 3 & - & 3 & 3 & AWD \\
\hline 9 & 179.6 & 86.4 & $\mathrm{cPR}$ & 12 & + & 37 & + & 37 & 46 & DOD \\
\hline 10 & 26.9 & 88.1 & $\mathrm{cPR}$ & 13 & - & 28 & + & 6 & 28 & DOD \\
\hline 11 & 642.5 & 100.0 & $\mathrm{cCR}$ & 8 & - & 21 & + & 4 & 21 & AWD \\
\hline 12 & 71.9 & 100.0 & $\mathrm{cCR}$ & 17 & - & 28 & - & 28 & 28 & $\begin{array}{l}\text { DOAD } \\
\text { (pancreatic } \\
\text { cancer) }\end{array}$ \\
\hline 13 & 176.9 & 78.7 & $\mathrm{cCR}$ & 10 & - & 72 & + & 4 & 72 & AWD \\
\hline 14 & 25.3 & 100.0 & $\mathrm{cCR}$ & 5 & - & 33 & - & 33 & 33 & NED \\
\hline 15 & 39.0 & 100.0 & $\mathrm{cCR}$ & 8 & - & 13 & + & 13 & 13 & DOD \\
\hline 16 & 4.2 & 100.0 & $\mathrm{cCR}$ & 17 & - & 62 & - & 62 & 62 & NED \\
\hline 17 & 29.5 & 100.0 & $\mathrm{cCR}$ & 9 & - & 59 & + & 11 & 59 & AWD \\
\hline 18 & 260.1 & 84.5 & $\mathrm{cPR}$ & 12 & - & 37 & + & 4 & 37 & AWD \\
\hline 19 & 68.2 & 90.8 & $\mathrm{cPR}$ & 5 & - & 8 & + & 1 & 8 & DOD \\
\hline 20 & 65.6 & 76.1 & cPR & 12 & - & 25 & + & 5 & 25 & AWD \\
\hline 21 & 23.7 & 100.0 & $\mathrm{cCR}$ & 16 & - & 16 & - & 16 & 16 & NED \\
\hline 22 & 116.7 & 74.7 & $\mathrm{cPR}$ & 7 & - & 17 & + & 9 & 17 & AWD \\
\hline 23 & 5.4 & 72.2 & $\mathrm{cPR}$ & 3 & + & 12 & + & 2 & 14 & DOD \\
\hline 24 & 20.3 & 100.0 & $\mathrm{cCR}$ & 9 & - & 9 & - & 9 & 9 & DOD \\
\hline 25 & 113.5 & 73.1 & $\mathrm{cPR}$ & 1 & - & 3 & + & 1 & 3 & AWD \\
\hline 26 & 35.7 & 100.0 & $\mathrm{cCR}$ & 7 & - & 7 & - & 7 & 7 & NED \\
\hline 27 & 7.2 & 100.0 & $\mathrm{cCR}$ & 5 & - & 11 & - & 11 & 11 & NED \\
\hline 28 & 26.2 & 89.3 & $\mathrm{cPR}$ & 6 & - & 9 & - & 9 & 9 & AWD \\
\hline 29 & 83.2 & 92.5 & $\mathrm{cPR}$ & 4 & - & 7 & - & 7 & 7 & AWD \\
\hline 30 & 78.1 & 91.4 & $\mathrm{cPR}$ & 5 & - & 7 & - & 7 & 7 & AWD \\
\hline
\end{tabular}

Pre-TTV, pre-treatment tumor volume; MTS, maximum tumor shrinkage; LC, local control; TTP, time to progression; cCR, clinical complete response; cPR, clinical partial response; NED, no evidence of disease; AWD, alive with disease; DOD, death of disease; DOAD, death of another disease.

products, are harmless to the human body. This suggests it is a safe sensitizer if proper dosage is used and attention is paid to avoid procedural problems such as incorrect administration into blood vessels (5). The severity of acute-phase adverse events, such as radio-dermatitis, has been reported to be comparable with that following adjuvant radiation for regular breast-conserving therapy (13-15). Also, no particular delay in acute-phase injuries has been observed. At our institution, we have used KORTUC II to treat over 250 cases of various solid cancers, including the LABC and LRBC reported in this article, but have observed no marked adverse reactions.

In our study, the 30 patients who underwent KORTUC II treatment experienced median MTS of $97 \%$, the cCR rate was $50 \%$, and the LC rate was $100,94.7$, and $75.4 \%$ at 1,2 , and 3 years, respectively (median follow-up period 19 months). Generally, excellent LC was obtained after therapy. Patients with LABC and LRBC have the potential for long term survival, and treatment that provides continuous symptom relief and local control is desired. The standard treatment for LABC is multidisciplinary treatment, with chemotherapy followed by local therapy such as surgery and RT (16-18). Twenty one of the 30 patients who received KORTUC treatment (70\%) experienced tumor re-growth, despite all having received chemo or hormonal therapy. Even in these cases, tumor shrinkage was also observed and QOL was improved. 


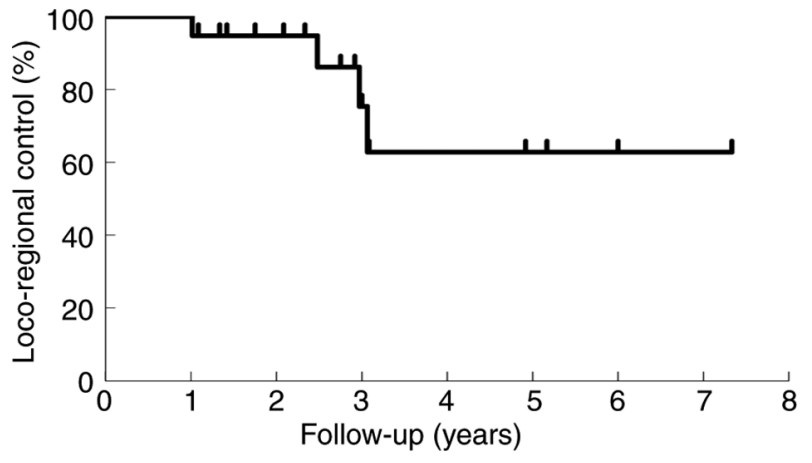

Figure 1. Kaplan-Meier curve of LC. The LC rates were $100,94.7$ and $75.4 \%$ at 1,2 and 3 years, respectively. LC, loco-regional control.

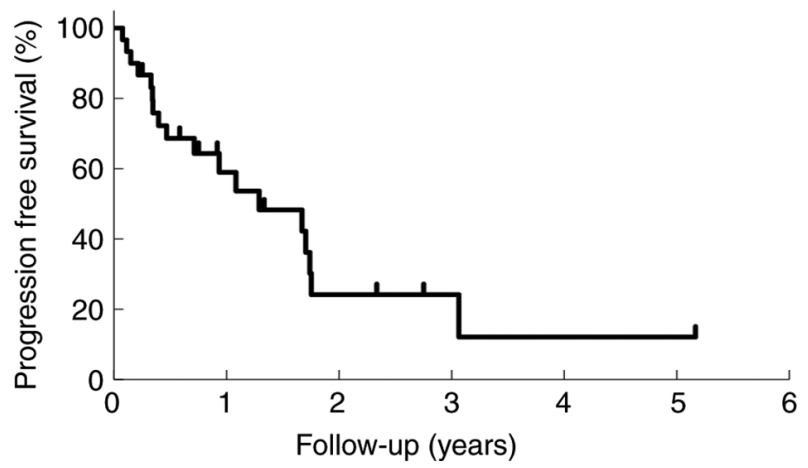

Figure 2. Kaplan-Meier curve of PFS after the completion of radiation therapy. The proportions with PFS were 59 and $24 \%$ of the 30 subjects at 1 and 2 years, respectively. PFS, progression free survival.

Regarding the radiation dose, it has been reported that irradiation of $30 \mathrm{~Gy}$ or more had a significant effect on symptom relief, and that patients who received $60 \mathrm{~Gy}$ or more at the primary site had a higher local control rate for 5 years compared with patients who received less than 60 Gy $(19,20)$. Sheldon et al (19) concluded that high-dose $\mathrm{RT}$ without mastectomy is an effective means of local control of LABC. In our case, we administered a high dose with a median 60.4 Gy3.5, but at this relatively high dose level there was no statistically significant difference in MTS, duration of LC and TTP depending on the irradiation dose. Although the responses of these 30 patients seems favorable considering their pre-treatment conditions, because individualized multidisciplinary treatment is used for LABC and LRBC, it would be difficult to compare the responses with those of patients who did not receive KORTUC II. Future well controlled cohort or retrospective case-control studies are necessary to address this issue.

Takaoka et al (21) reported the in vivo efficacy of radiotherapy combined with prior intratumoral $\mathrm{H}_{2} \mathrm{O}_{2}$ injection. A dose-modifying factor of 1.3-1.5 would be expected when combined with fractionated radiotherapy. If $3 \% \mathrm{H}_{2} \mathrm{O}_{2}$ were injected alone, it would cause severe pain at the injection site. However, diluting the sensitizer fivefold with sodium hyaluronate reduces this pain to a mild level in the experience of our institution. In addition, mixing the moderately viscous sodium hyaluronate with the sensitizer retards its enzymatic breakdown and dispersion, resulting in an elevated oxygen partial pressure inside the tumor for over $24 \mathrm{~h}(3,4,6,22)$. Therefore, twice-weekly intra-tumor local injection may be the best regimen, considering the sensitizing effects, need to limit patient discomfort, and the effort of injection.-Another major advantage is that $\mathrm{H}_{2} \mathrm{O}_{2}$ and sodium hyaluronate are inexpensive agents.

In addition, sodium hyaluronate itself may have the potential to suppress cancer progression and metastasis (23-26). It has highly metabolized in the lymphatic system, and migrates readily via lymphatic capillaries to regional lymph nodes following injection into breast tumor tissue (27-29). When accompanied by $\mathrm{H}_{2} \mathrm{O}_{2}$, these two compounds together can sensitize metastatic foci in lymph nodes. In the cases of KORTUC II treatment for first-episode breast cancer in our institution, we have experienced many cases of regression of axillary and supraclavicular fossa lymph node metastases in patients who received local injections of the sensitizer into the primary tumor, although none was injected into the metastatic nodes. CD44, which is highly expressed on the surface of cancer stem cells, is an adhesion molecule for which hyaluronic acid is a ligand $(26,30,31)$. This sensitizer is believed to target even the breast cancer stem cells (14).

Generally, KORTUC II aimed for local tumor control and symptom relief in patients with LABC and LRBC. Patients with unresectable LABC and LRBC often have severely compromised QOL, due to massive exudation and bleeding from the lesion, odor, and disfigurement. NCCN guidelines version 5. 2020 (32) recommends multidisciplinary treatment for LABC with a focus on drug therapy supplemented by surgery and RT. However, in many cases, regular RT fails to achieve satisfactory results for patients with unresectable tumors and many of these patients also do not respond to drug therapy. In this study, we have achieved significant local effects in the treatment of LABC and LRBC with a diameter of $10 \mathrm{~cm}$ or larger and open skin lesions. KORTUC II has improved greatly QOL and has been appreciated by the patients who received this therapy (15), suggesting it is a highly satisfactory treatment option.

Although the KORTUC II is effective in LC, it requires precautions, as soft tissue necrosis of the chest wall was observed in two patients after treatment. Their common features were that the tumor had invaded deep into the chest wall and the soft tissue necrosis occurred at the same time as the malignant lesions were expanding. The soft tissue necrosis may have been caused by inhibition of normal tissue recovery together with tumor tissue necrosis. Therefore, if imaging shows the tumor is invading deep into the chest wall and the tumor is growing rapidly, it may be best to forego or limit KORTUC II therapy to reduce the risk of soft tissue necrosis. It should be noted that soft tissue necrosis of the chest wall has also been reported with RT alone (33).

Many fundamental issues remain to be clarified related to KORTUC II, particularly quantified levels of patient benefit and how KORTUC II can be combined optimally with radiation, chemotherapy and immunotherapy to treat various cancers. To date only a single phase 1 clinical trial has been completed, and this showed no significant adverse effects in patients with LABC (34). Nimalasena et al (34) reported that injection pain was tolerable, dermatitis was not exacerbated, and the tumor regression rate was $50-100 \%$. 
Table III. Differences in selected parameters according to radiation dose (Wilcoxon rank sum test).

\begin{tabular}{lccr}
\hline Outcome & $<60$ Gy & $\geq 60$ Gy & P-value \\
\hline Number of patients (\%) & $7(23 \%)$ & $23(77 \%)$ & \\
EQD2(3.5), avg. Gy & 50.2 & 63.5 & $<0.01$ \\
Total number of injections, avg. & 4.4 & 4.9 & 0.40 \\
MTS, avg. \% & 86.1 & 93.4 & 0.09 \\
Duration of LC, avg. months & 30.3 & 23.7 & 0.49 \\
TTP, avg. months & 8.4 & 14.5 & 0.30 \\
\hline
\end{tabular}

There was no significant difference in total number of sensitizer injections, MTS, duration of LC and TTP. avg., average; EQD2(3.5), equivalent dose in 2 Gy fractions with the $\alpha / \beta$ ratio of 3.5 ; MTS, maximum tumor shrinkage; LC, local control; TTP, time to progression.

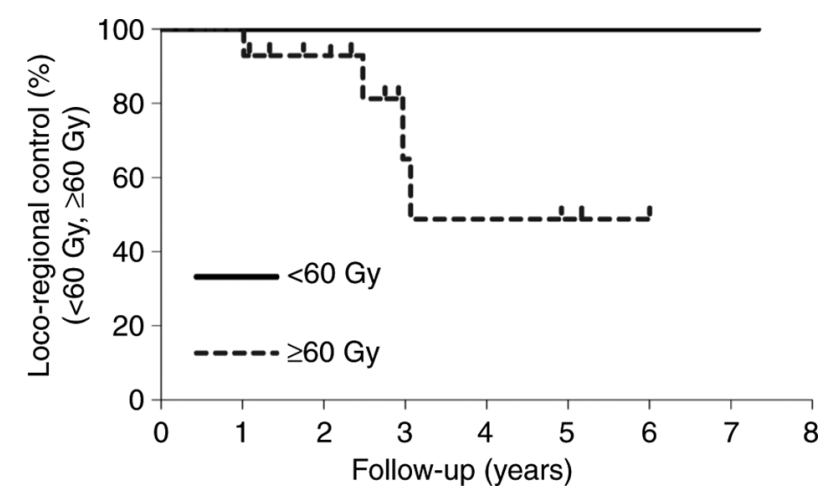

Figure 3. Kaplan-Meier curve of $\mathrm{LC}(<60$ and $\geq 60 \mathrm{~Gy})$. Wilcoxon $\mathrm{P}=0.19$. There was no difference in duration of LC between the two groups ( $<60$ and $\geq 60$ Gy). LC, loco-regional control.

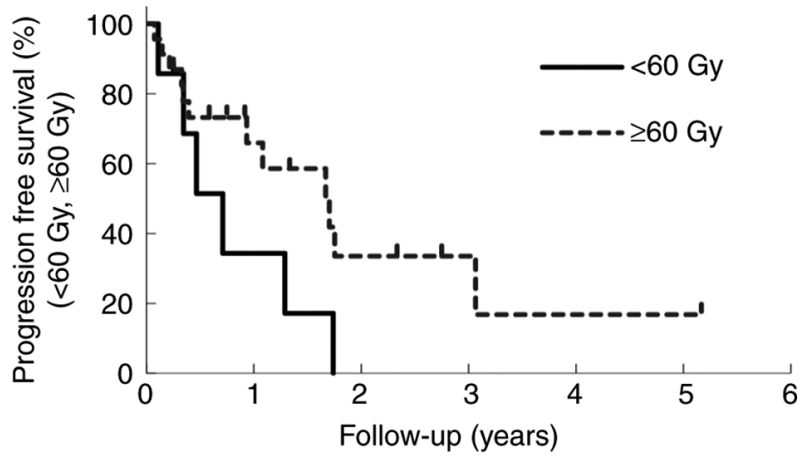

Figure 4. Kaplan-Meier curve of PFS ( $<60$ and $\geq 60$ Gy). Wilcoxon $P=0.21$. There was no difference in duration of PFS between the two groups ( $<60$ and $\geq 60 \mathrm{~Gy}$ ). PFS, progression free survival.

Biomarker tests demonstrated significant changes in IL-4, MIP-1 $\alpha$, IL-1 $\beta$, and TRAIL compared with those of the patient group without sensitizer, suggesting apoptosis induced by TNF-related apoptosis-inducing ligands associated with activated T-cell signaling and increased macrophage stimulation (34). Kariya et al (35) reported that $\mathrm{H}_{2} \mathrm{O}_{2}$ enhanced lysosome-dependent $\mathrm{X}$-ray-induced apoptosis in an in vitro experiment. A phase 2 study has been underway in five sites in the United Kingdom since June 2020-the only phase 2 trial to date. In the future, we need more clinical trials to promote widespread use of KORTUC II and to include it within insurance coverage.

In conclusion, KORTUC II demonstrated high rates of LC for LABC and LRBC. These effects may not be achievable with regular RT alone. Moreover, this method can play a major role in alleviating symptoms. KORTUC II is expected to be an inexpensive and extremely promising mode of RT with an excellent radiosensitizing effect.

\section{Acknowledgements}

The authors would like to thank Dr Yasuhiro Ogawa(Department of Radiation Oncology, Kochi General Rehabilitation Hospital, Kochi, Japan), visionary inventor of the KORTUC.

\section{Funding}

No funding was received.

\section{Availability of data and materials}

The datasets used and/or analyzed during the current study are available from the corresponding author on reasonable request.

\section{Authors' contributions}

TS and KN designed the study and wrote the manuscript. TS, YU and HA analyzed and interpreted the patient's clinical data for the manuscript. TS, MN, HY, CS, AH, KK and MI performed the KORTUC treatment and statistical analysis. KY contributed to collecting the relevant literature and to data analysis, and reviewed and critically interpreted the information. TS and HY confirm the authenticity of all the raw data. All authors have read and approved the final manuscript.

\section{Ethics approval and consent to participate}

Written informed consent was obtained from all patients. Approval was obtained from the Ethics Committee of Osaka Medical College (Osaka, Japan), trial no. 1973 (May 10, 2010).

\section{Patient consent for publication}

The patients provided written informed consent for the publication.

\section{Competing interests}

The authors declare that they have no competing interests.

\section{References}

1. Ogawa Y, Kubota K, Ue H, Nishioka A, Kariya S, Yokota N, Sasaki T, Suzuki K, Nakatani K, Yamanishi T, et al: Development and clinical application of a new radiosensitizer containing hydrogen peroxide and hyaluronic acid sodium for topical tumor injection-A new enzyme-targeting radiosensitization treatment, KORTUC II (Kochi Oxydol-Radiation Therapy for Unresectable Carcinomas, Type II). Strahlenther Onkol 183: 100-101, 2007. 
2. Ogawa Y, Ue H, Tsuzuki K, Tadokoro M, Miyatake K, Sasaki T, Yokota N, Hamada N, Kariya S, Hitomi J, et al: New radiosensitization treatment (KORTUC I) using hydrogen peroxide solution soaked gauze bolus for unresectable and superficially exposed neoplasms. Oncol Rep 19: 1389-1394, 2008.

3. Ogawa Y, Kubota K, Ue H, Kataoka Y, Tadokoro M, Miyatake K, Tsuzuki K, Yamanishi T, Itoh S, Hitomi J, et al: Phase I study of a new radiosensitizer containing hydrogen peroxide and sodium hyaluronate for topical tumor injection: A new enzyme-targeting radiosensitization treatment, Kochi Oxydol-Radiation Therapy for Unresectable Carcinomas, Type II (KORTUC II). Int J Oncol 34: 609-618, 2009.

4. Tokuhiro S, Ogawa Y, Tsuzuki K, Akima R, Ue H, Kariya S and Nishioka A: Development of a novel enzyme-targeting radiosensitizer (KORTUC) containing hydrogen peroxide for intratumoral injection for patients with low linear energy transfer-radioresistant neoplasms. Oncol Lett 1: 1025-1028, 2010

5. Ogawa Y, Kubota K, Ue H, Tadokoro M, Matsui R, Yamanishi T, Hamada N, Kariya S, Nishioka A, Nakajima H, et al: Safety and effectiveness of a new enzyme-targeting radiosensitization treatment (KORTC II) for intratumoral injection for low-LET radioresistant tumors. Int J Oncol 39: 553-560, 2011.

6. Ogawa Y: Paradigm shift in radiation biology/radiation oncology-exploitation of the ' $\mathrm{H}_{2} \mathrm{O}_{2}$ effect' for radiotherapy using low-LET (linear energy transfer) radiation such as $\mathrm{X}$-rays and high-energy electrons. Cancers (Basel) 8: 28, 2016.

7. Holloway CL,Panet-Raymond V and OlivottoI:Hypofractionation should be the new 'standard' for radiation therapy after breast conserving surgery. Breast 19: 163-167, 2010.

8. Qi XS, White J and Li XA: Is $\alpha / \beta$ for breast cancer really low? Radiother Oncol 100: 282-288, 2011.

9. Karim AB, Faber DB, Haas RE, Hoekstra FH and Njo KH: Metronidazole as a radiosensitizer: A preliminary report on estimation in serum and saliva. Int $\mathrm{J}$ Rad Oncol Biol Phys 6: 1233-1236, 1980.

10. Carabell SC, Bruno LA, Weinstein AS, Richter MP, Chang CH, Weiler CB and Goodman RL: Misonidazole and radiotherapy to treat malignant glioma: A phase II trial of the radiation therapy oncology group. Int J Radiat Oncol Biol Phys 7: 71-77, 1981.

11. Jette DC, Wiebe LI and Chapman JD: Synthesis and in vivo studies of the radiosensitizer4-(82Br) bromo-misonidazole. Int J Nucl Med Biol 10: 205-201, 1983.

12. Coleman CN: Hypoxic cell radiosensitizers: Expectations and progress in drug development. Int J Rad Oncol Biol Phys 11: 323-329, 1985

13. Aoyama N, Ogawa Y, Yasuoka M, Ohgi K, Iwasa H, Miyatake K, Yoshimatsu R, Yamanishi T, Hamada N, Tamura T, et al: Therapeutic results of a novel enzyme-targeting radiosensitization treatment, Kochi oxydol-radiation therapy for unresectable carcinomas II, in patients with stage I primary breast cancer. Oncol Lett 13: 4741-4747, 2017.

14. Ogawa Y, Kubota K, Aoyama N, Yamanishi T, Kariya S, Hamada N,Nogami M,Nishioka A, Onogawa M and Miyamura M: Non-surgical breast-conserving treatment (KORTUC-BCT) using a new radiosensitization method (KORTUC II) for patients with stage I or II breast cancer. Cancers (Basel) 7: 2277-2289, 2015.

15. Shibamoto Y, Murai T, Suzuki K, Hashizume C, Ohta K, Yamada Y, Niwa M, Torii A and Shimohira M: Definitive radiotherapy with SBRT or IMRT boost for breast cancer: Excellent local control and cosmetic outcome. Technol Cancer Res Treat 17: 1533033818799355, 2018.

16. Costa R, Hansen N and Gradishar WJ: Locally advanced breast cancer. Breast e6: 819-831, 2018.

17. Gröhn P, Heinonen E, Klefström P and Tarkkanen J: Adjuvant postoperative radiotherapy, chemotherapy, and immunotherapy in stage III breast cancer. Cancer 54: 670-674, 1984.

18. Early Breast Cancer Trialists' Collaborative Group (EBCTCG): Effects of chemo-therapy and hormonal therapy for early breast cancer on recurrence and 15-year survival: An overview of the randomised trials. Lancet 365: 1687-1717, 2005.

19. Sheldon T, Hayes DF, Cady B, Parker L, Osteen R, Silver B, Recht A, Come S, Henderson IC and Harris JR: Primary radiation therapy for locally advanced breast cancer. Cancer 60 : $1219-1225,1987$
20. Vempati P, Knoll MA, Dharmarajan K, Green S, Tiersten A and Bakst RL: Palliation of ulcerative breast lesions with radiation. Anticancer Res 36: 4701-4705, 2016.

21. Takaoka T, Shibamoto Y, Matsuo M, Sugie C, Murai T, Ogawa Y, Miyakawa A, Manabe Y, Kondo T, Nakajima K, et al: Biological effects of hydrogen peroxide administered intratumorally with or without irradiation in murine tumors. Cancer Sci 108: 1787-1792, 2017.

22. Aoyama N, Ogawa Y, Yasuoka M, Takahashi M, Iwasa H, Miyatake K, Yamanishi T, Hamada N, Tamura T, Nishioka A and Yamagami T: Therapeutic response to a novel enzyme-targeting radiosensitization treatment (Kochi Oxydol-Radiation Therapy for Unresectable Carcinomas) in patients with recurrent breast cancer. Oncol Lett 12: 29-34, 2016.

23. Ooki T, Murata-Kamiya N, Takahashi-Kanemitsu A, Wu W and Hatakeyama M: High-molecular-weight hyaluronsan is a hippo pathway ligand directing cell density-dependent growth inhibition via PAR1b. Dev Cell 49: 590-604.e9, 2019.

24. Witschen PM, Chaffee TS, Brady NJ, Huggins DN, Knutson TP, LaRue RS, Munro SA, Tiegs L, McCarthy JB, Nelson AC and Schwertfeger KL: Tumor cell associated hyaluronan-CD44 signaling promotes pro-tumor inflammation in breast cancer. Cancers (Basel) 12: 1325, 2020.

25. Han W, Song L, Wang Y, Lv Y, Chen X and Zhao X: Preparation, characterization, and inhibition of hyaluronic acid oligosaccharides in triple-negative breast cancer. Biomolecules 9: 436, 2019.

26. Bourguignon LY, Shiina M and Li JJ: Hyaluronan-CD44 interaction promotes oncogenic signaling, microRNA functions, chemoresistance, and radiation resistance in cancer stem cells leading to tumor progression. Adv Cancer Res 123: 255-275, 2014.

27. Pandey MS, Harris EN, Weigel JA and Weigel PH: The cytoplasmic domain of the hyaluronan receptor for endocytosis (HARE) contains multiple endocytic motifs targeting coated pit-mediated internalization. J Biol Chem 283: 21453-21461, 2008.

28. Weigel JA, Raymond RC, McGary C, Singh A and Weigel PH: A blocking antibody to the hyaluronan (HA) receptor for endocytosis (HARE) inhibits HA clearance by perfused liver. J Biol Chem 278: 9808-9812, 2003

29. Zhou B, Weigel JA, Saxena A and Weigel PH: Molecular cloning and functional expression of the rat $175-\mathrm{kDa}$ hyaluronan receptor for endocytosis. Mol Biol Cell 13: 2853-2868, 2002.

30. Al-Hajj M, Wicha MS, Benito-Hernandez A, Morrison SJ and Clarke MF: Prospective identification of tumorigenic breast cancer cells. Proc Natl Acad Sci USA 100: 3983-3988, 2003.

31. Dick JE: Breast cancer stem cells revealed. Proc Natl Acad Sci USA 100: 3547-3549, 2003.

32. NCCN guidelinrs version 5.2020 Breast cancer. Available from: https://www2.tri-kobe.org/nccn/guideline/breast/english/breast. pdf.

33. Wahl AO, Rademaker A, Kiel KD, Jones EL, Marks LB, Croog V, McCormick BM, Hirsch A, Karkar A, Motwani SB, et al: Multi-institutional review of repeat irradiation of chest wall and breast for recurrent breast cancer. Int J Rad Oncol Biol Phys 70: 477-484, 2008

34. Nimalasena S, Gothard L, Anbalagan S, Allen S, Sinnett V, Mohammed K, Kothari G, Musallam A, Lucy C, Yu S, et al: Intratumoral hydrogen peroxide with radiation therapy in locally advanced breast cancer: Results from a phase 1 clinical trial. Int J Rad Oncol Biol Phys 108: 1019-1029, 2020.

35. Kariya S, Sawada K, Kobayashi T, Karashima T, Shuin T, Nishioka A and Ogawa Y: Combination treatment of hydrogen peroxide and $\mathrm{x}$-rays induces apoptosis in human prostate cancer PC-3 cells. Int J Rad Oncol Biol Phys 75: 449-454, 2009.

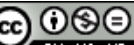

This work is licensed under a Creative Commons Attribution-NonCommercial-NoDerivatives 4.0 International (CC BY-NC-ND 4.0) License. 